\title{
Effects of Magnesium Sulfate Attack on Ordinary Portland Cement (OPC) Mortars
}

\author{
M. M. Amin ${ }^{1, *}$, S. B. Jamaludin', F. C. Pa ${ }^{1}$, K. K. Chuen ${ }^{2}$ \\ ${ }^{I}$ School of Materials Engineering, University Malaysia Perlis, \\ Complex Taman Muhibah UniMAP, 02600 Jejawi, Perlis, Malaysia \\ ${ }^{2}$ Department of Chemistry, Faculty of Science and Technology, University Malaysia \\ Terengganu, Kuala Terengganu, Malaysia
}

Received 23 May 2007; accepted 8 October 2007

\begin{abstract}
The chemical and mineralogical compositions in Ordinary Portland Cement (OPC) were determined and cement which is low of $\mathrm{C}_{3} \mathrm{~A}$ is more easily exposed to sulfate environment. The relation between physical strength of mortars sized $150 \times 150 \times 150$ $\mathrm{mm}$ and the effects of different concentrations of sulfate solutions, $\mathrm{SO}_{4}{ }^{2-}(1 \%, 3 \%$ and $5 \%$ ) for 3, 14 and 28 days was found to be that stronger the sulphate concentrations, the greater the sulfate attack, but in a weaker concentration situation, the attack was more efficient as the comparable damaged being achieved with smaller amount of sulphate. The morphological studies were observed under scanning electron microscope (SEM) and the distribution of the main component, including $\mathrm{Mg}^{2+}$ and $\mathrm{SO}_{4}{ }^{2-}$ ions, was analysed by Energy Dispersive X-Ray Analyzer (EDS) to observe the cracks and reactions.
\end{abstract}

Keywords: Ordinary Portland Cement (OPC), magnesium sulfate, sulfate attack, SEM.

\section{Introduction}

Sulfate attack is consider one of the major deteriorative problems occurred when the cement based materials, such as concrete, mortars and buildings, are exposed to this environment. Sulphate ions in soil, ground water and sea water may cause deterioration of reinforced concrete structures by provoking expansion and cracking due to factors such as type of cement, sulphate cation type, sulphate concentration and the period of exposure. Many structures affected by sulphate degradation often need to be repaired or, in most severe cases, they need to be

\footnotetext{
*Corresponding author. E-mail address: mmamin@unimap.edu.my; amin_56@yahoo.com
} 
reconstructed [1-3]. Three main factors are reported [4-5]: properties; aggressive medium and environmental atmosphere.

The present investigation was carried out to determine the chemical compositions in cement and the effect of magnesium sulphate of different concentrations on the surfaces of mortars, followed by observing the changes of strength by measuring through compression tests. The morphological structures of the mortars exposed in sulphate solutions were observed using scanning electron microscope (SEM) and studied by EDS (Energy Dispersive X-Ray Analyzer). The investigations help to clarify the great importance of understanding the physical strength of mortars exposed in sulphate environments and there are not many reported results. The spallation and cracking are produced due to sulphate ions by exposure to containing inorganic salts atmospheres.

\section{Experimental}

Mortar cubes $(150 \times 150 \times 150 \mathrm{~mm})$ established from cement, sand and water ratio of 2.5, 7.5 and 1.0, respectively, with the sand size $20 \mathrm{~mm}$ (fine aggregates clean river sand) were prepared and exposed in magnesium sulfate solution $(10,000 \mathrm{mg} / \mathrm{L}, 30,000 \mathrm{mg} / \mathrm{L}$ and $50,000 \mathrm{mg} / \mathrm{L})$ for 3,14 and 28 days at room temperature. The mortar cubes were moulded in metal moulds which are not attacked by cement or sand. The cube specimens were rigidly constructed in such a way as to facilitate the removal of the moulded specimen without damage. After the exposure period, the mortars were taken out for compressive strength, followed by SEM and EDS tests.

Chemical and mineralogical analysis of the cement were carried out to determine the main components such as: $\mathrm{SiO}_{2}, \mathrm{R}_{2} \mathrm{O}_{3}, \mathrm{CaO}, \mathrm{MgO}, \mathrm{Fe}_{2} \mathrm{O}_{3}, \mathrm{Al}_{2} \mathrm{O}_{3}, \mathrm{SO}_{3}$. Based on the oxide components, the Bogue analysis was determined. Table 1 shows the main components of Ordinary Portland Cement and the calculation of the oxides composition.

Table 1. Main components of Ordinary Portland Cement [3].

\begin{tabular}{lcc}
\hline Name of compound & Oxide composition & Abbreviation \\
\hline Tricalcium silicate & $3 \mathrm{CaO}^{-\mathrm{SiO}_{2}}$ & $\mathrm{C}_{3} \mathrm{~S}$ \\
Dicalcium silicate & $2 \mathrm{CaO} \cdot \mathrm{SiO}_{2}$ & $\mathrm{C}_{2} \mathrm{~S}$ \\
Tricalcium aluminate & $3 \mathrm{CaO} \cdot \mathrm{Al}_{2} \mathrm{O}_{3}$ & $\mathrm{C}_{3} \mathrm{~A}$ \\
Tetracalcium & $4 \mathrm{CaO} \cdot \mathrm{Al}_{2} \mathrm{O}_{3} \cdot \mathrm{Fe}_{2} \mathrm{O}_{3}$ & $\mathrm{C}_{4} \mathrm{AF}$ \\
aluminoferrite & & \\
\hline
\end{tabular}

$$
\begin{aligned}
& \mathrm{C}_{3} \mathrm{~S}=4.07(\mathrm{CaO})-7.60\left(\mathrm{SiO}_{2}\right)-6.72\left(\mathrm{Al}_{2} \mathrm{O}_{3}\right)-1.43\left(\mathrm{Fe}_{2} \mathrm{O}_{3}\right)-2.85\left(\mathrm{SO}_{3}\right) \\
& \mathrm{C}_{2} \mathrm{~S}=2.87\left(\mathrm{SiO}_{2}\right)-0.75\left(3 \mathrm{CaO} . \mathrm{SiO}_{2}\right) \\
& \mathrm{C}_{3} \mathrm{~A}=2.65\left(\mathrm{Al}_{2} \mathrm{O}_{3}\right)-1.69\left(\mathrm{Fe}_{2} \mathrm{O}_{3}\right) \\
& \mathrm{C}_{4} \mathrm{AF}=3.04\left(\mathrm{Fe}_{2} \mathrm{O}_{3}\right)
\end{aligned}
$$


The morphological studies of the mortars were conducted using scanning electron microscope (SEM) and combined with energy dispersive X-ray analyser (EDS) to observe the distribution of ions and the attack.

\section{Results and discussion}

\section{Chemical and mineralogical analysis}

Chemical and mineralogical analysis results are presented in Table 2.

Table 2. Chemical and mineralogical analysis of the OPC.

\begin{tabular}{lc}
\hline \multicolumn{1}{c}{ Oxides } & Ordinary Portland Cement (OPC) /\% \\
\hline $\mathrm{SiO}_{2}$ & 21.47 \\
$\mathrm{R}_{2} \mathrm{O}_{3}$ & 6.51 \\
$\mathrm{CaO}$ & 60.77 \\
$\mathrm{MgO}$ & 0.17 \\
$\mathrm{Fe}_{2} \mathrm{O}_{3}$ & 2.34 \\
$\mathrm{Al}_{2} \mathrm{O}_{3}$ & 4.17 \\
$\mathrm{SO}_{3}$ & 2.71 \\
$\mathrm{Insoluble}$ residue & 0.39 \\
Loss on ignition & 1.31 \\
& \\
Bogue analysis & \\
$\mathrm{C}_{3} \mathrm{~S}$ & \\
$\mathrm{C}_{2} \mathrm{~S}$ & 45.07 \\
$\mathrm{C}_{3} \mathrm{~A}$ & 27.82 \\
$\mathrm{C}_{4} \mathrm{AF}$ & 7.10 \\
\hline
\end{tabular}

\section{Compressive strength analysis}

The compressive strength of mortars, illustrated in Fig. 1, indicates that after long exposure time periods into the weaker solution (1\%), the sulphate attack was more efficient than when subjected to stronger sulphate concentrations during short periods. 


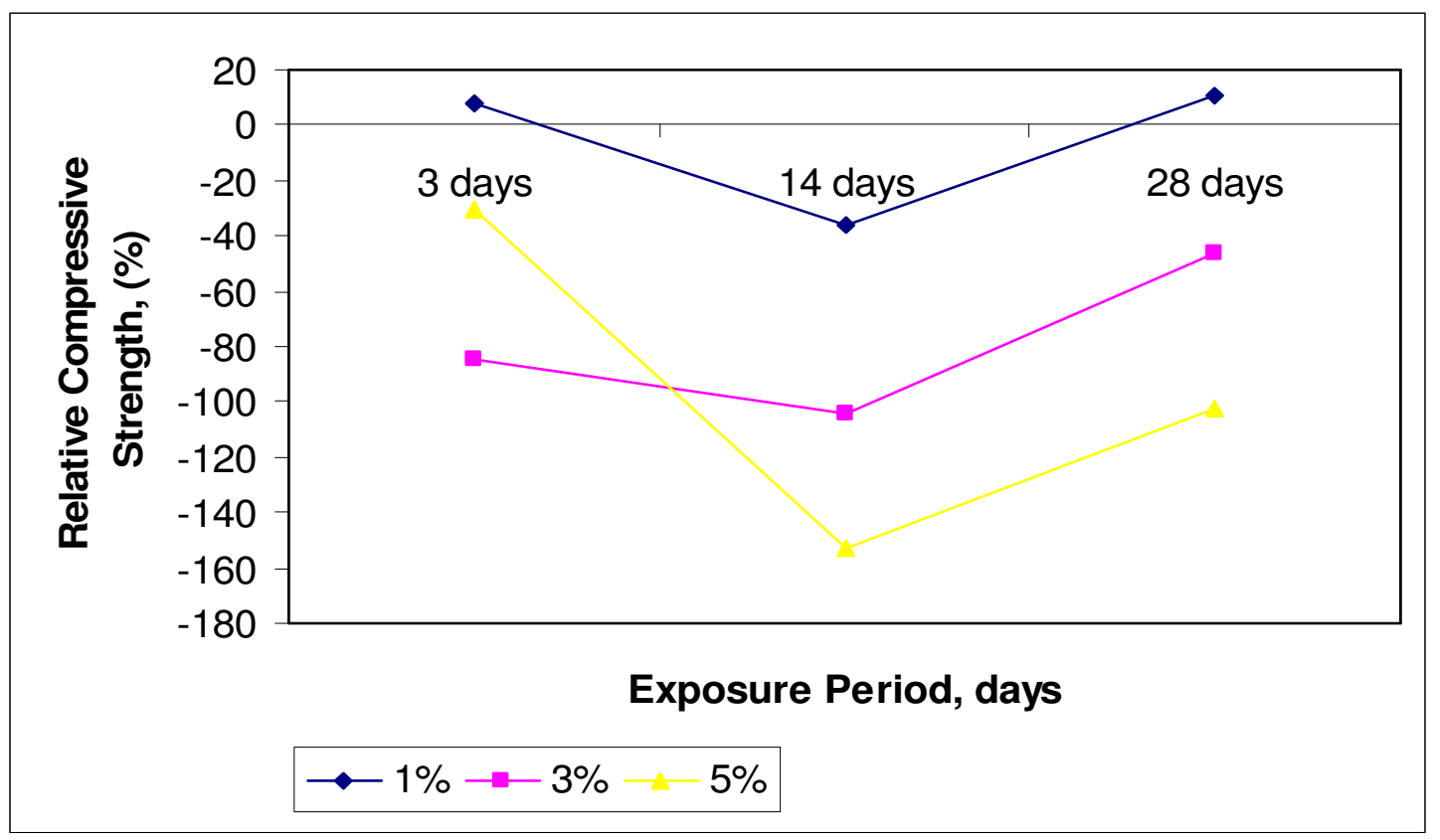

Figure 1. Relative compressive strength / (\%) after exposure in 1, 3 and $5 \% \mathrm{MgSO}_{4}$ solution for 3, 14 and 28 days.

\section{Surface analysis at different concentrations}

Precipitation of salts in the inner part of the mortars is shown in Fig. 2 ( $a$ and b). It is observed that the precipitating of salts around the specimen at 5\% solution is greater than in the $3 \%$ solution.

\section{Morphological analysis under SEM}

Scanning electron microscope was used to observe the morphological structure on the surface layer and inner part of the specimens under EDS. Besides, it was determined the formation of thaumasite and ettringite in the specimen after exposure.

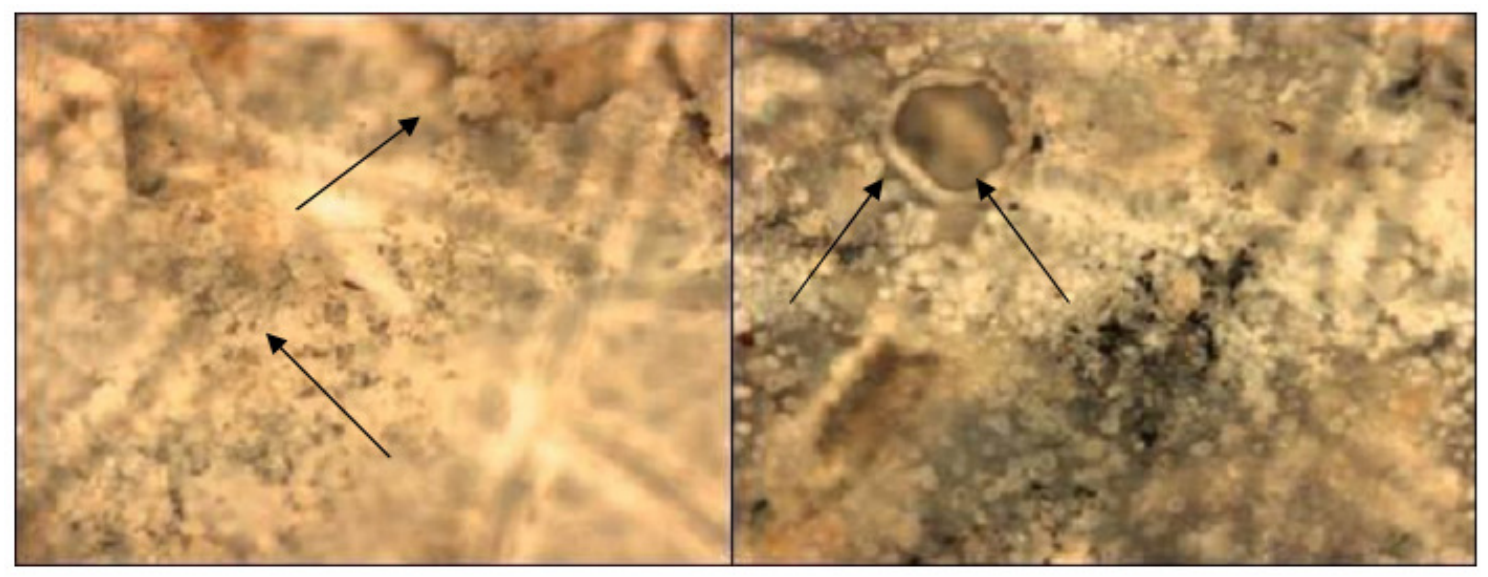

( a )

(b)

Figure 2. Surface of mortars with precipitation of $\mathrm{MgSO} 4$ salts after exposure in (a) $30,000 \mathrm{mg} / \mathrm{L}$ and (b) $50,000 \mathrm{mg} / \mathrm{L}$ solution for 28 days. 
The SEM image in Fig. 3 shows mortars specimen exposed in the sulfate concentrations of $50,000 \mathrm{mg} / \mathrm{L}$ for 28 days. The specimen used in the micrograph vacuum is taken from an area close to the edge of the mortar at low vacuum and shows the morphology of the inner and outer parts of the specimen which then were used to obtain the sub-micron volume of the specimen at the area 006 and 007 using EDS (Energy Dispersive X-Ray Analyzer).

It is observed the presence of a cracked area at the left bottom (marked in colour) along the paste interfaces which is caused by the formation of ettringite. It is not filled in with white colour materials because the exposure time period was not long enough for the formation of effringite; the white material filling in the cracked area consists of needle-like crystals with lengths ranging between 2 and $6 \mu \mathrm{m}$. EDS analysis were carried out to determine ettringite or thaumasite [4].

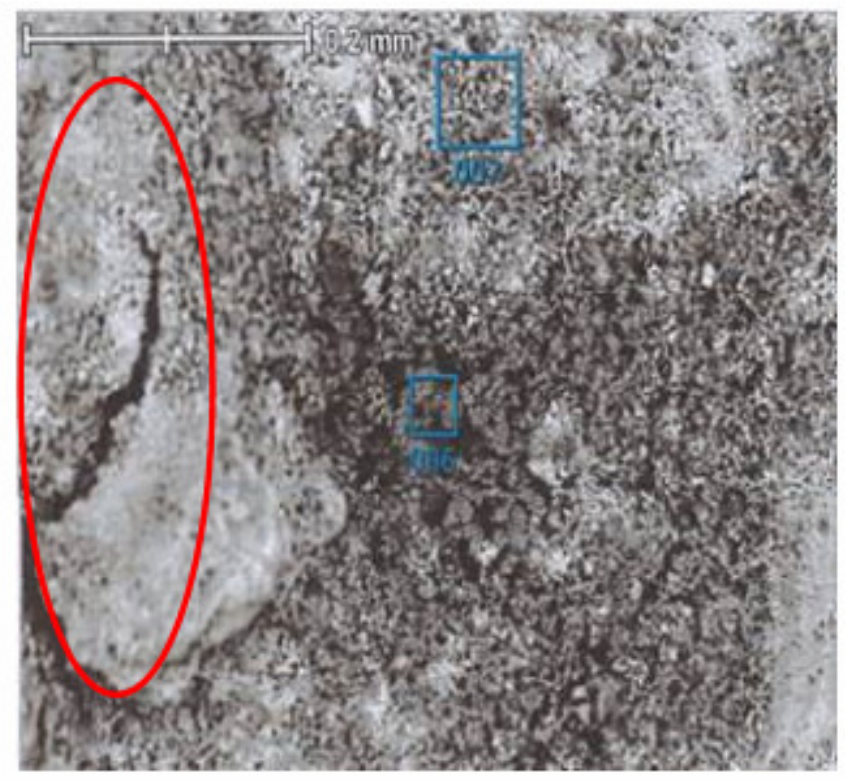

Figure 3. Morphology of specimen attacked by $5 \% \mathrm{MgSO}_{4}$ solutions for 28 days. The region (006) and (007) are the inner part and the outer part, respectively.

Table 3. Mass in percentage of the main chemical components at 006 and 007 regions.

\begin{tabular}{cccccccc}
\hline Region & $\mathrm{C}$ & $\mathrm{O}$ & $\mathrm{Mg}$ & $\mathrm{Si}$ & $\mathrm{S}$ & $\mathrm{Ca}$ & Total \\
\hline 006 & 6.44 & 56.77 & 25.93 & 0.72 & 0.41 & 9.73 & 100.00 \\
007 & 6.21 & 54.04 & 13.49 & 2.02 & 0.46 & 23.78 & 100.00 \\
\hline
\end{tabular}

Fig. 4 shows the presence of $\mathrm{Ca}, \mathrm{Si}$ and $\mathrm{S}$, whereas $\mathrm{Al}$ is almost absent. Thus, it can be concluded that thaumasite is present. The presence of high $\mathrm{Mg}$ and $\mathrm{O}$ indicates that the specimen is attacked by the magnesium ions with the formation of magnesium hydroxide (brucite) and the conversion of $\mathrm{C}-\mathrm{S}-\mathrm{H}$ into magnesium silicate hydrate (M-S-H) occurred. 

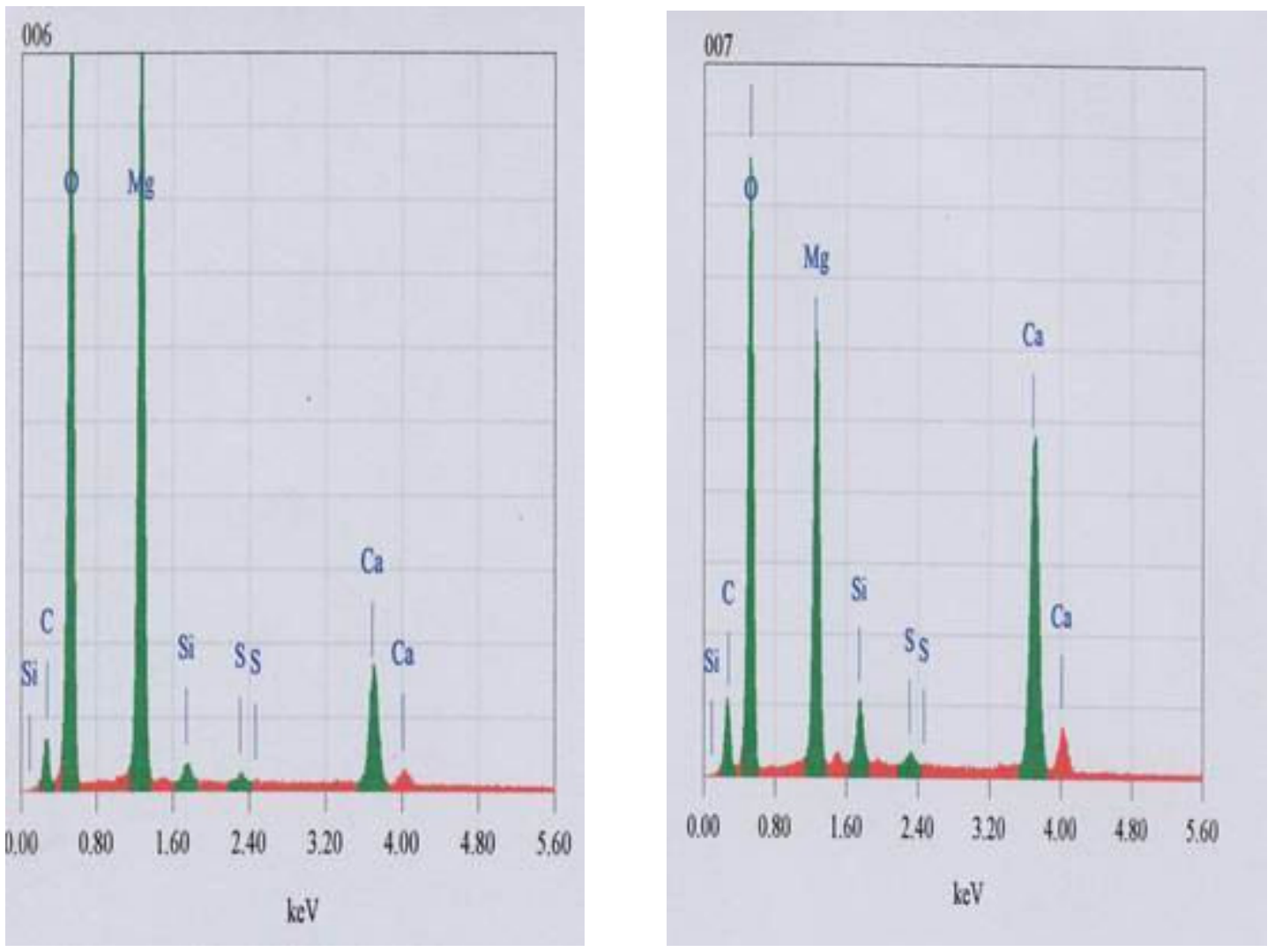

Figure 4. EDS spectrum at 006 and 007 regions with component peaks.

The mechanism of magnesium sulfate attack with cement hydrates as follows [6]:

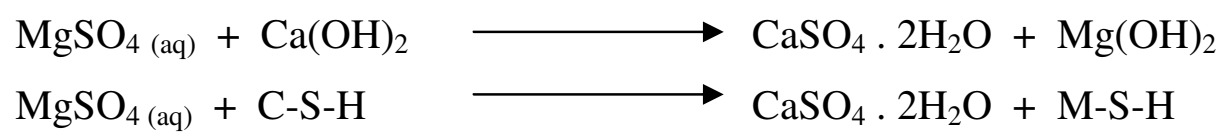

The presence of high $\mathrm{Mg}$ in the region is indicative of carbonation and of the region where the brucite deposits. Furthermore, in the magnesium sulfate solution, the increase in concentration led to higher rate of expansion. Comparing the values in Table 3, it results that the magnesium peak is higher in the 006 region with $25.93 \%$ of mass than in the 007 region with $13.49 \%$, which shows a difference of $12.44 \%$. This is because of the magnesium ions tend to attack the deeper surface and replacing the calcium.

$\mathrm{Ca}^{2+}$ and $\mathrm{OH}^{-}$are provided initially by dissolution of $\mathrm{CH}$ and the $\mathrm{Si} / \mathrm{Ca}$ ratio of the $\mathrm{C}-\mathrm{S}-\mathrm{H}$ begins to increase only when the $\mathrm{CH}$ has been depleted; it also implies the use of $\mathrm{Ca}^{2+}$ in the formation of gypsum [6]. By comparing mass percentage of regions 006 and 007, it is seen that when the area with high magnesium precipitates, the percentage of calcium becomes lesser and the magnesium percentage being low, suggests a high calcium percentage.

Fig. 5 shows a near-surface microstructure of a mortar after being immersed in $\mathrm{MgSO}_{4}$ solution of concentration $50,000 \mathrm{mg} / \mathrm{L}$ during 28 days and the distribution of the main components. As a result, based on the distribution of 
magnesium ions, shown in green, the magnesium cation tends to attack the inner area of the mortar which is about $2 \mathrm{~mm}$ depth. At the area with highest magnesium concentration, it can be seen that the calcium started to become lesser at the same spot.
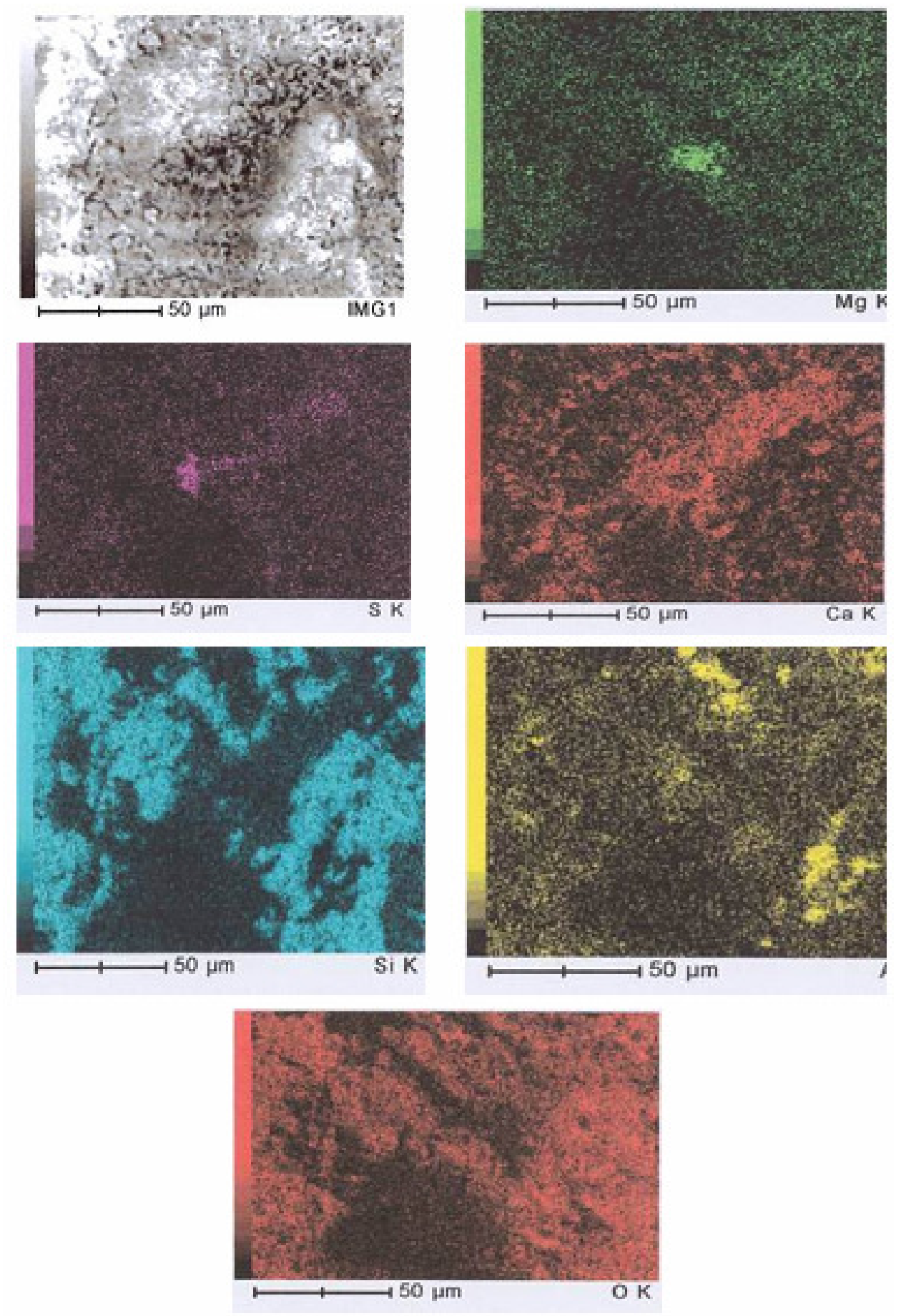

Figure 5. Distribution of $\mathrm{Mg}, \mathrm{S}, \mathrm{Ca}, \mathrm{Si}, \mathrm{Al}$ and $\mathrm{O}$ in the microstructure using EDS elemental mapping.

$\mathrm{Mg}^{2+}$ and $\mathrm{SO}_{4}{ }^{2-}$ ions independently make a line of attack into different regions, which consists of calcium at the deeper region of the surface, exhibiting the 
formation of the crystalline salt at the first stage. The following stages are the formation of ettringite and gypsum which play an important role in softening the materials, causing cracking. The formation of gypsum has a close relationship with the $\mathrm{Ca}(\mathrm{OH})_{2}$ content [7].

\section{Conclusions}

Based on the results of this study, it is concluded:

The chemical and mineralogical composition in the Ordinary Portland Cement (OPC) were determined, following SEM and EDS techniques.

The formation of ettringite at the early stage causes cracking, thus being related to the expansion which is the cause of damage in the cement paste.

Damage caused by the sulphate attack is attributed to decalcification, which weakens the $\mathrm{C}-\mathrm{S}-\mathrm{H}$ matrix and partly the formation of ettringite, which causes cracking and expansion.

The resistance of mortars to sulfate attack was influenced by the content of the interfacial zone, which means the higher the content of interfacial zone, the faster the cement mortar expanded. In order to improve the structure of the interfacial zone, pre-treated quartz aggregate, which is composed of hydraulic surface layer and inert core, can be used.

$\mathrm{Mg}^{2+}$ and $\mathrm{SO}_{4}{ }^{2-}$ ions make a line of attack into different regions which consists of calcium at the deeper region of the surface, resulting on the formation of the crystalline salt.

\section{References}

1. J. Marchand, E. Samson, Y. Maltais, J.J. Beaudoin. Cement and Concrete Composites 24 (2002) 317-329.

2. E.E. Hekal, E. Kishar, H. Mostafa. Cement and Concrete Research 32 (2004) 1421-1427.

3. A.M. Neville, Properties of Concrete, $4^{\text {th }}$ ed., Longman Group Limited, London, 1995.

4. S.M. Torres, J.H. Sharp, R.N. Swamy, C.J. Lynsdale, S.A. Huntley. Cement and Concrete 25 (2003) 947-954.

5. M. Santhanam, M.D. Cohen, J. Olek, Mechanism of sulfate attack: A fresh look. Part 1: Summary of experimental results, West Lafayette, U.S.A., Cement and Concrete Research 32 (2002) 915-921.

6. R.S. Gollop, H.F.W. Taylor. Cement and Concrete Research 26 (1996) 1013-1028.

7. H. Biricik, F. Akoz, F. Turker, I. Berktay. Cement and Concrete Research 30 (2000) 1189-1197. 